\title{
Outcomes of post-cardiac surgery patients with persistent hyperlactatemia in the intensive care unit: a matched cohort study
}

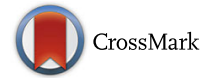

\author{
Nicole T. J. J. Mak', Sameena lqbal' ${ }^{2}$, Benoit de Varennes ${ }^{3}$ and Kosar Khwaja ${ }^{4 *}$
}

\begin{abstract}
Background: Higher morbidity and mortality rates are seen amongst patients presenting with hyperlactatemia in the postoperative period. The purpose of this study was to determine the relationship between persistent elevations in lactate and poor ICU outcome in post-cardiac surgery patients.

Methods: This was a retrospective matched cohort analysis of cardiac surgery patients undergoing bypass and/or valve surgery in a university hospital centre. Selection criteria were: cardiac bypass and/or valve surgery; admission to the ICU for $>24 \mathrm{~h}$ postoperatively; and peak lactate $\geq 3.0 \mathrm{mmol} / \mathrm{L}$. Hyperlactatemic patients were matched to 2 normolactatemic patients. Multivariable conditional logistic regression was used to determine predictors of hyperlactatemia and mortality.

Results: Four hundred sixty-nine post-cardiac surgery patients were admitted to the ICU for $>24 \mathrm{~h}$. 144 of these patients had an arterial blood lactate $\geq 3.0 \mathrm{mmol} / \mathrm{L}$. Amongst the mortalities, $78.9 \%$ presented with hyperlactatemia. Independent risk factors predictive of a lactate $\geq 3.0 \mathrm{mmol} / \mathrm{L}$ were preoperative IABP insertion (RR $2.8, \mathrm{Cl} 1.1-7.2$ ) and postoperative acute kidney injury (RR 3.2, $\mathrm{Cl}$ 2.1-5.4). Patients whose lactate concentrations continued to increase $>30 \mathrm{~h}$ postoperatively were more likely to die (RR $8.44 \mathrm{Cl} 2.50-28.53$ ).

Conclusions: The persistence of hyperlactatemia is a more important determinant of postoperative outcome than the absolute value of the peak lactate concentration. A simple postoperative lactate washout does not sufficiently explain this lactate accumulation. Mortality is proposed to be secondary to a state of ongoing hypoperfusion.
\end{abstract}

Keywords: Lactate, Surgery, Cardiac, Surgical intensive care, Acidosis, Lactic, Postoperative care

\section{Background}

A product of anaerobic metabolism, lactate is a biomarker and indicator for tissue hypoperfusion and oxygen debt $[1,2]$. In anaerobic metabolism, pyruvate is converted to lactate so that, in conditions of hypoxia, energy may continue to be derived from glucose. Pathological causes of lactic acidosis include those conditions causing tissue hypoxia: pulmonary disease leading to low $\mathrm{P}_{\mathrm{O} 2}$; circulatory shock with decreased oxygen delivery; and decreased hemoglobin and oxygen carrying capacity $[3,4]$. Lactic acidosis secondary to hypoxia or hypoperfusion is known as "type A" lactate acidosis. A

\footnotetext{
*Correspondence: kosar.khwaja@mcgill.ca

${ }^{4}$ Departments of Surgery and Critical Care Medicine, McGill University Health

Centre, 1650 Cedar Ave. L9.411, Montréal, QC H3G 1A4, Canada

Full list of author information is available at the end of the article
}

rise in lactate may also be of the " $\mathrm{B}$ " type, which is due to a lack of lactate clearance by the liver and kidneys.

Lactate concentrations are measured regularly in the intensive care unit (ICU) and elevated blood lactate is a common finding post-cardiac surgery. In the critically ill patient, a normal blood lactate is less than $2 \mathrm{mmol} / \mathrm{L}$. High postoperative serum lactate levels have been previously associated with an increased risk of postoperative mortality and poor outcome in both adult and pediatric cardiac surgery populations [2-10]. Lactate is also a biomarker and potential prognostic tool in the acute care setting. In adult surgical patients, greater mortality rates are seen amongst patients in whom lactate levels normalize more slowly. Non-normalizing lactate levels have been associated with a $100 \%$ postoperative mortality rate [5]. 
In this matched cohort study, we describe postoperative outcome in a population of hyperlactatemic cardiac surgery patients. An analysis of the relationship between hyperlactatemia, time to peak lactate concentrations and postoperative mortality was performed. The predictors of elevated lactate were determined and the value of serial lactate measurements evaluated.

\section{Methods}

\section{Study population and matched controls}

A retrospective chart review was conducted on patients undergoing cardiac surgery at the Royal Victoria Hospital (Montreal, Quebec) from January 2011 to December 2011, inclusive. Inclusion criteria were: 1) elective or emergent coronary artery bypass and/or valve surgery, 2) admission to the ICU for postoperative care $>24 \mathrm{~h}$ in duration, 3) peak arterial blood lactate $\geq 3.0 \mathrm{mmol} / \mathrm{L}$ (Fig. 1). Each hyperlactatemic patient was matched to 2 control patients selected from cardiac surgery patients whose operation occurred between January 2010 and December 2012. Cases and controls were matched for sex, age, surgery type, Parsonnet score (a risk estimation score of patient preoperative factors including diabetes, left ventricular ejection fraction, re-operative status, and dialysis-dependence) and 2 preoperative comorbidities associated with mortality risk-renal failure and peripheral vascular disease. Patients without matched controls were excluded from analysis where appropriate.

\section{Data collection}

Preoperative data including comorbidities and risk stratification scores were obtained from the hospital's cardiac surgery database. Postoperative data was collected from the intensive care unit database and the hospital's clinical information system database. Additionally, patients presenting with lactate $\geq 3.0 \mathrm{mmol} / \mathrm{L}$ in the ICU underwent a chart review. Postoperative data collected was limited to events occurring during the ICU stay. Mortality was defined as death during the cardiac surgery hospital stay. Serial postoperative lactate values for each patient with arterial blood lactate values $\geq 3.0 \mathrm{mmol} / \mathrm{L}$ were trended to determine the time to the peak lactate value. This was defined as the number of hours elapsed between the surgery end-time to the time of peak sample collection. Preoperative baseline serum creatinine concentrations were recorded to determine the occurrence of new acute kidney injury using the Acute Kidney Injury Network (AKIN) stage 1 criteria. Lastly, diagnostic interventions performed in the ICU such as CT, MRI, echocardiogram, or ultrasound were noted.

\section{Statistical methods}

Statistical analyses were performed using the SAS System (SAS 9.3 Institute, Cary, NC). Patient characteristics were summarized using proportions, medians, and ranges as appropriate. The data was analysed in two parts. First, a cohort study of the patients with lactate $\geq 3.0 \mathrm{mmol} / \mathrm{L}$ was conducted to determine outcomes. This was followed by a matched cohort study to assess risk factors for hyperlactatemia and mortality.

For the cohort study, student's t-tests or Wilcoxon's rank-sum and Kruskal-Wallis tests were used to compare clinical variables of survivors and non-survivors. Variables with univariate significance were entered into the Cox Proportional Hazard regression model which assessed the effect of time to the development of abnormally high serum lactate levels while controlling for possible confounders. A categorical variable was created for the $90^{\text {th }}$ percentile for time to peak lactate concentrations (30 h). Kaplan Meier
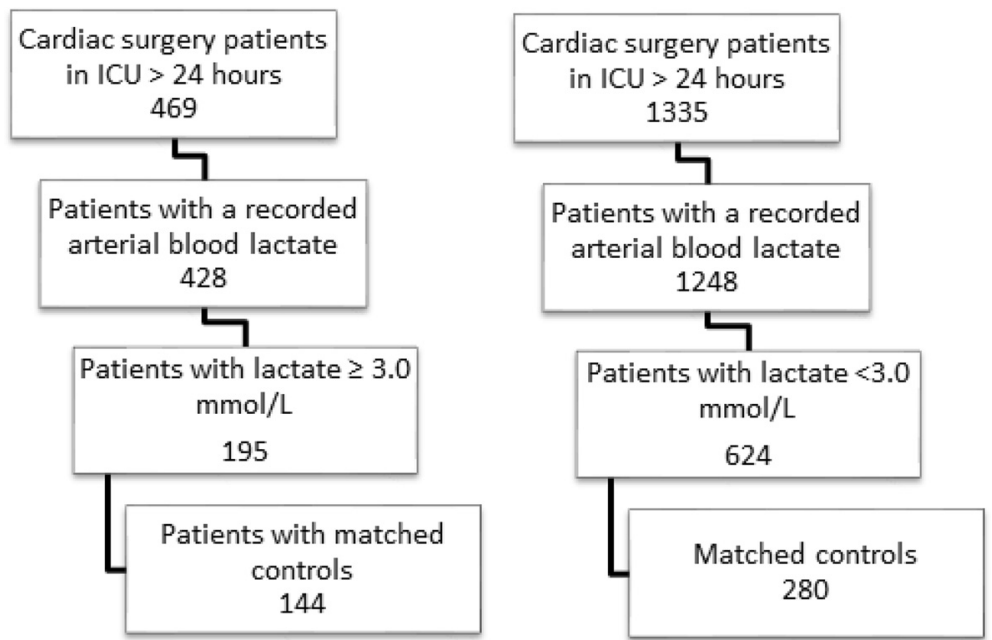

Fig. 1 Selection criteria of cases (a) and controls (b) for the matched cohort study 
curves were created to depict the survival curves for those reaching peak lactate before and after $30 \mathrm{~h}$.

In the matched cohort analysis, Wilcoxon's rank-sum and Kruskal-Wallis tests were used to compare clinical variables between normolactatemic and hyperlactatemic patients as well as between survivors and non-survivors. The individually matched cases and controls were analyzed using conditional logistic regression through the Cox Proportional Hazard model with strata. Variables with univariate significance were entered into the model and predictors for in-hospital mortality were determined. Generalized estimating equations for binary data were used to assess the association of elevated serum lactate levels with postoperative intra-aortic balloon pump (IABP).

Data are presented as the following, as appropriate: number (proportion in percentage), median (range), hazard ratio $(95 \% \mathrm{CI})$. A $p$-value $<0.05$ was considered significant.

This study was approved by the McGill University Health Centre ethics review board. No patient consent was required.

\section{Results}

\section{Patient demographics}

Postoperative lactate $\geq 3.0 \mathrm{mmol} / \mathrm{L}$ was observed in 195 cases out of the 428 patients reviewed. The procedures performed in the patient population included 279 coronary artery bypass grafts (CABG), 29 aortic valve repairs/replacements (AVR), 23 mitral valve repairs/replacements (MVR), 45 CABG + AVR, 7 CABG + MVR, and 4 MVR + tricuspid valve repair/replacement. The matched groups had similar preoperative characteristics for the variables for which they were matched. Baseline demographics and preoperative comorbidities of cases and controls are found in Table 1. Data was non-normally distributed and therefore the median was used to describe and compare cases with controls. Prevalence of preoperative cardiogenic shock and IABP insertion was higher in patients with postoperative peak lactate $\geq 3.0 \mathrm{mmol} / \mathrm{L}$. The matched controls had a higher frequency of chronic obstructive pulmonary disease and diabetes mellitus.

\section{Postoperative outcomes}

A summary of postoperative complications is presented in Table 1. The median peak postoperative arterial blood lactate amongst the cases was $4.6 \mathrm{mmol} / \mathrm{L}$. That of the matched controls was $2.1 \mathrm{mmol} / \mathrm{L}$. Over $15 \%$ of cases returned to the operating room (OR) for further intervention: 8 for hemorrhage/re-exploration, 4 for pericardial effusion, 2 for perforated bowel, 2 for bowel ischemia/obstruction, 2 for peripheral ischemia and 1 for left ventricular assist device. By contrast, only $1.8 \%$ of controls returned to the OR for hemorrhage/re-exploration. The use of IABP was more frequently employed in those with
Table 1 Comparison of demographics and perioperative course of cases and controls

\begin{tabular}{|c|c|c|c|}
\hline & $\begin{array}{l}\text { Cases } \\
(n=144)\end{array}$ & $\begin{array}{l}\text { Controls } \\
(n=280)\end{array}$ & $p$-value \\
\hline \multicolumn{4}{|l|}{ Preoperative characteristics } \\
\hline Gender (male) & $93(64.6 \%)$ & $181(64.6 \%)$ & 1.00 \\
\hline Age (years) & $70(43-89)$ & $70(42-89)$ & 0.81 \\
\hline Parsonnet score & $18.3(0-49.0)$ & $16.5(0-52.5)$ & 0.28 \\
\hline Renal failure ${ }^{a}$ & $22(15.3 \%)$ & $29(10.4 \%)$ & 0.16 \\
\hline $\begin{array}{l}\text { Severe peripheral vascular } \\
\text { disease }\end{array}$ & $13(9 \%)$ & $17(6.1 \%)$ & 0.32 \\
\hline Cardiogenic shock ${ }^{b}$ & $5(3.5 \%)$ & $1(0.4 \%)$ & 0.02 \\
\hline $\begin{array}{l}\text { Preoperative intra-aortic } \\
\text { balloon pump }\end{array}$ & $16(11.1 \%)$ & $10(3.6 \%)$ & 0.004 \\
\hline $\begin{array}{l}\text { Chronic obstructive } \\
\text { pulmonary disease }\end{array}$ & $10(6.9 \%)$ & 48 (17.1\%) & 0.004 \\
\hline Diabetes $^{d}$ & $38(26.4 \%)$ & $103(36.8 \%)$ & 0.04 \\
\hline \multicolumn{4}{|l|}{ Postoperative characteristics } \\
\hline Peak lactate (mmol/L) & $4.6(3.0-18.0)$ & $2.1(0.8-2.9)$ & $<0.0001$ \\
\hline $\begin{array}{l}\text { Peak serum creatinine } \\
\text { level }(\mathrm{mmol} / \mathrm{L})\end{array}$ & $127(66-840)$ & $100(39-1013)$ & $<0.0001$ \\
\hline Intra-aortic balloon pump & $29(20.1 \%)$ & $14(5 \%)$ & $<0.0001$ \\
\hline $\begin{array}{l}\text { Computed tomography } \\
\text { chest /abdomen }\end{array}$ & $4(2.8 \%)$ & 0 & 0.01 \\
\hline Return to operating room & $22(15.3 \%)$ & $5(1.8 \%)$ & $<0.0001$ \\
\hline Cardiogenic shock & $9(6.3 \%)$ & $2(0.7 \%)$ & 0.002 \\
\hline $\begin{array}{l}\text { Post-operative cardiac } \\
\text { hemorrhage }\end{array}$ & $9(6.3 \%)$ & $4(1.4 \%)$ & 0.01 \\
\hline Acute kidney injury (AKIN 1) & 68 (50.4 \%) & $73(26.8 \%)$ & $<0.0001$ \\
\hline Ischemic bowel & $1(0.7 \%)$ & 0 & 0.34 \\
\hline $\begin{array}{l}\text { Length of ICU admission } \\
\text { (days) }\end{array}$ & $3(1-96)$ & $1(1-29)$ & $<0.0001$ \\
\hline ICU readmission & $12(8.3 \%)$ & $13(4.7 \%)$ & 0.13 \\
\hline Mechanical ventilation (days) & $0.89(0.14-75.5)$ & $0.50(0.09-11.9)$ & $<0.0001$ \\
\hline Mortality & 15 (10.4\%) & $4(1.4 \%)$ & $<0.0001$ \\
\hline
\end{tabular}

Cases presented with peak lactate $\geq 3.0 \mathrm{mmol} / \mathrm{L}$ in the postoperative ICU admission while controls had a peak lactate $<3.0 \mathrm{mmol} / \mathrm{L}$. Data is expressed as: number of patients (frequency in percentage) or median (range)

${ }^{a}$ Acute or chronic renal failure

bWith urinary output $<10 \mathrm{cc} / \mathrm{hr}$

${ }^{c}$ Chronic obstructive pulmonary disease on medical treatment

${ }^{\mathrm{d}}$ Diabetes on insulin or oral hypoglycemic agents

hyperlactatemia $(\mathrm{p}<0.0001)$. A significantly higher occurrence of complications such as cardiogenic shock (6.3\%, $p=0.002)$, cardiac hemorrhage $(6.3 \%, p=0.01)$, and acute kidney injury $(50.4 \%, p<0.0001)$ were also observed. Renal dysfunction was further characterized by comparing serum creatinine levels. Preoperative baseline serum creatinine levels were similar between both groups but peak postoperative creatinine was found to be higher in those presenting with lactate $>3.0 \mathrm{mM}$. No significant difference was found with respect to the usage of angiography but 
more CT scans of the chest and/or abdomen were conducted for the hyperlactatemic patients.

Among the cases and controls, length of ICU stay, time on mechanical ventilation and hospital mortality were measured (Table 1). With respect to these measures, hyperlactatemic patients had poorer outcomes, having a longer ICU stay (3 vs. 1 days, $p<0.0001$ ), greater time on mechanical ventilation ( 0.89 vs 0.50 days, $p<0.0001)$, and higher hospital mortality $(p<0.0001)$. The mortality rate amongst hyperlactatemic patients was $10.4 \%$ compared to $1.4 \%$ in the controls. No differences were found in the length of hospital admission or the frequency of ICU readmission.

A comparison between survivors and non-survivors was conducted in the cohort as well as in the matched-control analyses. Comparative analysis revealed that, among the cases of hyperlactatemia, non-survivors had a mean Parsonnet score of 31.5, compared to a score of 16.75 in survivors (Table 2). Non-survivors were more often patients with pre-existing renal failure, chronic obstructive pulmonary disease (COPD), hypertension and heart failure. Emergent surgery, longer cardiopulmonary bypass $(\mathrm{CPB})$ time and requirement for postoperative IABP were also observed to be significantly increased in non-survivors. The mean CPB time amongst those who died was $153 \mathrm{~min}$ compared to $110 \mathrm{~min}$ in those that survived $(p=0.01)$. Death was associated with a higher peak lactate (10.2 vs $4.4 \mathrm{mmol} / \mathrm{L}, p=0.0002$ ) and a delayed time to peak lactate. The $90^{\text {th }}$ percentile for time to peak lactate was $30 \mathrm{~h}$. A significantly greater proportion of non-survivors surpassed the $90^{\text {th }}$ percentile: in $64.7 \%$ of mortalities, lactate peak was reached at $>30 \mathrm{~h}(p<0.0001)$. On average, hyperlactatemic non-survivors attained their peak lactate in $37.6 \mathrm{~h}$ compared to $7.5 \mathrm{~h}$ in survivors $(p<0.0001)$. Again, differences were noted with respect to renal function. Acute kidney injury was more frequent in non-survivors. Peak creatinine and percentage rise in postoperative creatinine were also greater.

Comparative analysis of non-survivors and survivors in the matched-control population showed that preoperative renal failure, severe peripheral vascular disease and reoperation were associated with mortality while age and congestive heart failure approached significance (Table 3). The majority of patients who died presented with hyperlactatemia (78.9 \%) and the 28-day mortality amongst hyperlactatemic patients was $5.6 \%$ (8/144 patients). Mortality in the study population was associated with a higher incidence of postoperative surgical interventions, IABP and complications such as cardiogenic shock, cardiac hemorrhage, and renal dysfunction.

Table 2 Comparison of perioperative characteristics of mortality and survival amongst hyperlactatemic patients

\begin{tabular}{|c|c|c|c|}
\hline & Non-survivors $(n=17)$ & Survivors $(n=127)$ & $p$-value \\
\hline \multicolumn{4}{|l|}{ Pre-operative characteristics } \\
\hline Gender (male) & $9(52.9 \%)$ & $84(66.1 \%)$ & 0.29 \\
\hline Age (years) & $75(56-87)$ & $70(43-89)$ & 0.12 \\
\hline Parsonnet score & $31.5(17.0-49.0)$ & $16.8(0-46.5)$ & $<0.0001$ \\
\hline Parsonnet score greater than 31 & $20(15.8 \%)$ & $9(52.9 \%)$ & 0.001 \\
\hline Operation status (emergency) & $3(17.7 \%)$ & $14(11.5 \%)$ & 0.03 \\
\hline Surgery type & & & 0.36 \\
\hline Dialysis & $3(17.7 \%)$ & $3(2.4 \%)$ & 0.02 \\
\hline Chronic Obstructive Pulmonary Disease & $4(23.5 \%)$ & $6(4.7 \%)$ & 0.02 \\
\hline Congestive Heart Failure & $11(64.7 \%)$ & $50(39.4 \%)$ & 0.05 \\
\hline \multicolumn{4}{|l|}{ Post-operative characteristics } \\
\hline Cardiopulmonary Bypass time (min) & $153(83-214)$ & $110(25-302)$ & 0.01 \\
\hline Post-operative Intra-aortic Balloon Pump & $8(47.1 \%)$ & $21(16.5 \%)$ & 0.003 \\
\hline Time to peak lactate $>30 \mathrm{~h}$ & $11(64.7 \%)$ & $3(2.4 \%)$ & $<0.0001$ \\
\hline Time to peak lactate (hours) & $37.6(1.3-385)$ & $7.5(0.25-755.5)$ & $<0.0001$ \\
\hline Peak arterial lactate (mmol/L) & $10.2(2.4-18)$ & $4.4(1.7-13.1)$ & 0.0002 \\
\hline Total Mechanical Ventilation Days & $3.14(0-76.5)$ & $0.89(0.14-44.1)$ & 0.0001 \\
\hline Acute kidney injury & $16(100 \%)$ & $64(51.6 \%)$ & 0.0002 \\
\hline Peak creatinine ( $\mu \mathrm{mol} / \mathrm{L})$ & $309(107-738)$ & $119(66-840)$ & $<0.0001$ \\
\hline Postoperative rise in creatinine (\%) & 30 (-80 to 254$)$ & 164 (31 to 660$)$ & $<0.0001$ \\
\hline
\end{tabular}

Cases presented with peak lactate $\geq 3.0 \mathrm{mmol} / \mathrm{L}$ in the postoperative ICU admission. Data is expressed as: number of patients (frequency in percentage) or median (range) 
Table 3 Comparison of survival and non-survival amongst cases and controls: demographics and perioperative characteristics

\begin{tabular}{|c|c|c|c|}
\hline & $\begin{array}{l}\text { Non-survivors } \\
(n=19)\end{array}$ & $\begin{array}{l}\text { Survivors } \\
(n=405)\end{array}$ & $p$-value \\
\hline \multicolumn{4}{|l|}{ Preoperative characteristics } \\
\hline Gender (male) & $11(57.9 \%)$ & $263(64.9 \%)$ & 0.62 \\
\hline Age (years) & $75(56-87)$ & $70(42-89)$ & 0.05 \\
\hline Parsonnet score & $30.5(16.5-49)$ & $16.5(0-52.5)$ & $<0.0001$ \\
\hline Congestive heart failure & $12(63.2 \%)$ & 170 (41.9 \%) & 0.06 \\
\hline Renal failure ${ }^{a}$ & $9(47.4 \%)$ & $42(10.4 \%)$ & $<0.0001$ \\
\hline $\begin{array}{l}\text { Severe peripheral vascular } \\
\text { disease }\end{array}$ & $5(26.3 \%)$ & $25(6.2 \%)$ & 0.007 \\
\hline Reoperation & $3(15.8 \%)$ & $8(2 \%)$ & 0.005 \\
\hline $\begin{array}{l}\text { Chronic obstructive } \\
\text { pulmonary disease }\end{array}$ & $7(36.8 \%)$ & $51(12.6 \%)$ & .008 \\
\hline \multicolumn{4}{|l|}{ Postoperative characteristics } \\
\hline $\begin{array}{l}\text { Peak arterial lactate } \\
\geq 3.0 \mathrm{mmol} / \mathrm{L}\end{array}$ & $15(78.9 \%)$ & $129(31.8 \%)$ & $<0.0001$ \\
\hline Peak creatinine $\mu \mathrm{mol} / \mathrm{L}$ & $127(66-840)$ & $100(39-1013)$ & $<0.0001$ \\
\hline Intra-aortic balloon pump & $6(31.6 \%)$ & $37(9.2 \%)$ & 0.008 \\
\hline $\mathrm{CT}$ chest /abdomen & $2(10.5 \%)$ & $2(0.5 \%)$ & 0.01 \\
\hline Return to OR & $5(26.3 \%)$ & $22(5.4 \%)$ & 0.005 \\
\hline Cardiogenic shock & $5(26.3 \%)$ & $6(1.5 \%)$ & $<0.0001$ \\
\hline $\begin{array}{l}\text { Post-operative cardiac } \\
\text { hemorrhage }\end{array}$ & $2(10.5 \%)$ & $11(2.7 \%)$ & 0.01 \\
\hline Acute kidney injury (AKIN 1) & $16(84.2 \%)$ & $125(32.2 \%)$ & $<0.0001$ \\
\hline Non-obstructive ileus & $1(5.5 \%)$ & $2(0.5 \%)$ & 0.13 \\
\hline Ischemic bowel & $1(5.5 \%)$ & 0 & 0.05 \\
\hline
\end{tabular}

Data is expressed as: number of patients (frequency in percentage) or median (range)

${ }^{\mathrm{a} A}$ Acute or chronic renal failure

${ }^{\mathrm{b}} \mathrm{COPD}$ on medical treatment

\section{Predictors of hyperlactatemia and mortality}

Conditional logistic regression was used to determine predictors of hyperlactatemia and mortality. Two factors predictive of a peak postoperative lactate $\geq 3.0 \mathrm{mmol} / \mathrm{L}$ were found: insertion of preoperative IABP and postoperative acute kidney injury. Adjusted hazard ratios are presented in Table 4. Patients requiring preoperative IABP insertion were 2.8 times more likely to develop hyperlactatemia (95\% CI 1.1-7.2). Acute kidney injury was associated with a hazard ratio of 3.2 (95\% CI 2.1-5.4).

Despite the association between hyperlactatemia and mortality on univariate analysis, the logistic regression model conducted did not find lactate $\geq 3.0 \mathrm{mmol} / \mathrm{L}$ to be a predictor of death. However, when analysing hyperlactatemic patients as a cohort, calculated hazard ratios showed that a delayed peak in lactate was strongly associated with death (Table 5). Patients who exceeded the $90^{\text {th }}$ percentile for time to peak lactate were 8.44 (95\% CI 2.50-28.53) times more likely to die. Survival curves illustrate that overall survival outcomes were better in
Table 4 Risk factors for lactate $\geq 3.0 \mathrm{mmol} / \mathrm{L}$ during the postoperative ICU admission

\begin{tabular}{lll}
\hline Variable & $\begin{array}{l}\text { Unadjusted OR } \\
(95 \% \mathrm{Cl})\end{array}$ & $\begin{array}{l}\text { Adjusted OR } \\
(95 \% \mathrm{Cl})\end{array}$ \\
\hline Diabetes status & $0.53(0.33-0.86)$ & $0.47(0.28-0.77)$ \\
$\begin{array}{l}\text { Preoperative intra-aortic } \\
\text { balloon pump }\end{array}$ & $3.0(1.2-7.3)$ & $2.8(1.1-7.2)$ \\
Acute kidney injury (AKIN 1) & $3.1(2.0-4.7)$ & $3.2(2.1-5.1)$ \\
\hline$n=424$ &
\end{tabular}

those who had a shorter duration of lactate rise (Fig. 2). Other risk factors for mortality were percentage increase in serum creatinine and Parsonnet score.

\section{Discussion}

The relationship between hyperlactatemia and poor outcome has been established in adult and pediatric populations. Mortality risk has been associated with both intraoperative and postoperative hyperlactatemia [2-17]. Lactate levels between 2.0 and $4.4 \mathrm{mmol} / \mathrm{L}$ have been reported to be associated with increased postoperative morbidity and mortality. Debate exists in the literature regarding which lactate measurement is most indicative of poor outcome. Some have measured lactate concentrations under $\mathrm{CPB}$ or peak postoperative lactate while others have found that lactate levels upon ICU admission were predictive of outcome [5, 7-13, 15-19]. Other studies in medical and surgical critical care have reported that better outcomes are observed in the presence of effective lactate clearance [6, 13, 19-23]. In sum, different parameters have been used to characterize the relationship between lactate and poor outcome. Furthermore, evidence exists to suggest that survivors may be in a metabolic state more favorable for early resolution of the hyperlactatemic state. It may be that, in critically ill patients with multi-organ dysfunction, duration of lactic acidosis has greater predictive value than that of initial lactate values at first presentation.

Lactate concentration is determined by both the production and clearance of lactate. An elevated lactate may be secondary to a previous state of anaerobic metabolism that has not yet been cleared. Therefore, the actual metabolic state of the patient may not be determined by a sole reliance on a lactate concentration. Given that hepatic and renal clearance is often impaired in the

Table 5 Adjusted and unadjusted hazard ratios for mortality in patients with peak postoperative lactate $\geq 3.0 \mathrm{mmol} / \mathrm{L}$

\begin{tabular}{lll}
\hline & $\begin{array}{l}\text { Adjusted HR } \\
(95 \% \mathrm{Cl})\end{array}$ & $\begin{array}{l}\text { Unadjusted HR } \\
(95 \% \mathrm{Cl})\end{array}$ \\
\hline Time to peak lactate $\geq 30 \mathrm{~h}$ & $8.44(2.50-28.53)$ & $7.13(2.17-23.45)$ \\
Percent rise in serum creatinine & $1.72(1.15-2.58)$ & $1.40(1.03-1.90)$ \\
Parsonnet score $>31$ & $5.21(1.07-25.44)$ & $0.80(0.24-2.65)$ \\
\hline
\end{tabular}




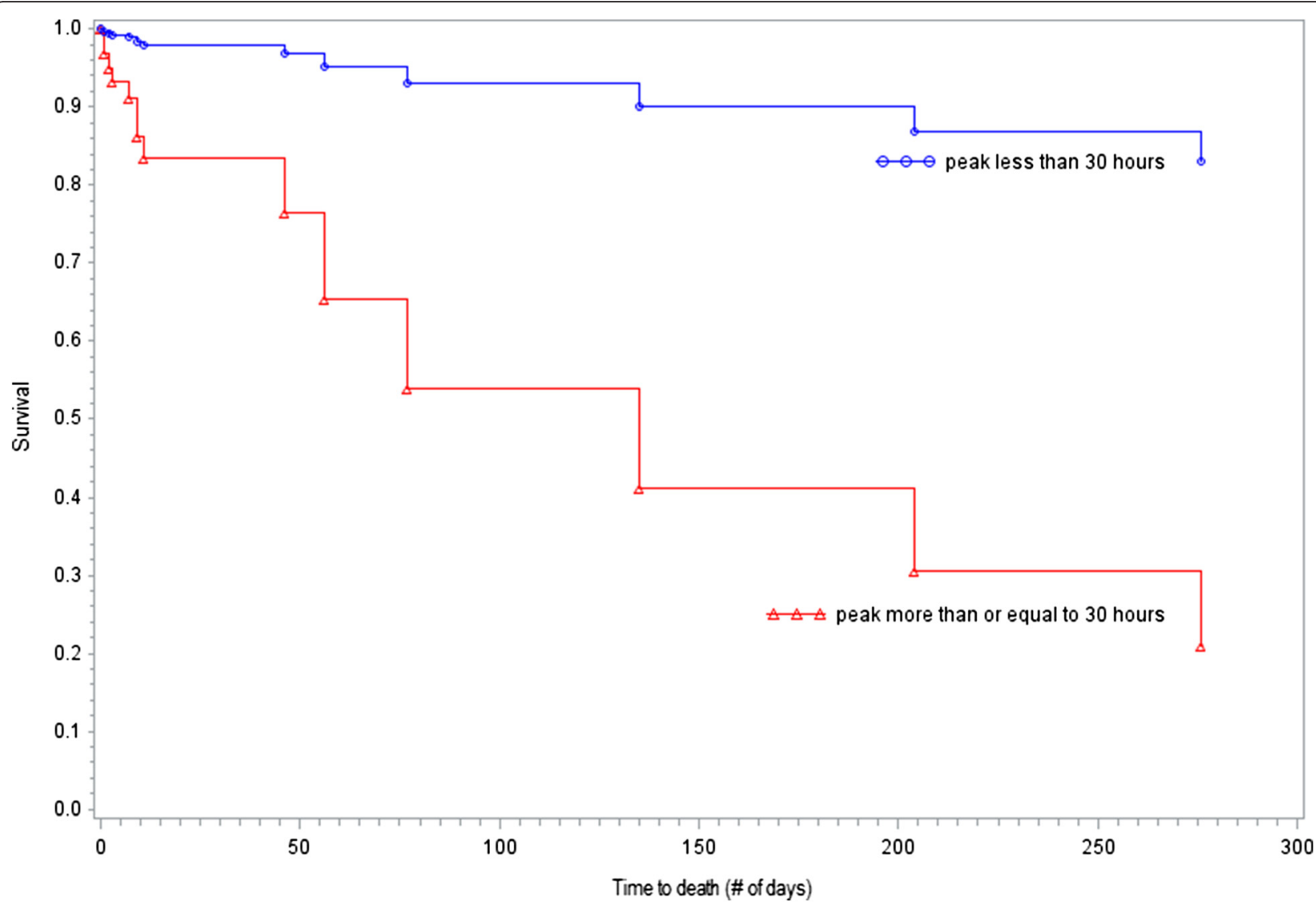

Fig. 2 Survival curve for cases of lactate $\geq 3.0 \mathrm{mmol} / \mathrm{L}$ showing survival probability for patients attaining peak lactate in $\geq 30 \mathrm{~h}$ (triangles) and those attaining their peak lactate in $<30 \mathrm{~h}$ (circles)

critically ill, it is reasonable to instead observe serial lactate measurements. In this study, lactate was followed until the peak concentration was reached. That is, measurements were followed so long as there was evidence of a continued imbalance in the production and clearance of lactate. It is expected that time to peak lactate is a better reflection of ongoing active metabolic dysfunction in the critically ill. One other study in the literature by Ranucci et al. is known to have employed a similar strategy. Theirs was a study of intraoperative anaerobic metabolism in patients on cardiopulmonary bypass [17].

The results of this study suggest that a single event of lactate $\geq 3.0 \mathrm{mmol} / \mathrm{L}$ is not a reliable predictor of mortality in post-cardiac surgery patients [24]. Instead a strong relationship was drawn between a late peaking lactate and mortality. A peak in lactate at $>30 \mathrm{~h}$ postoperatively was a highly significant risk factor for death in our population. This risk was independent of the absolute concentration of lactate in the blood, $\mathrm{CPB}$ time, Parsonnet score and use of postoperative IABP. Two other risk factors with a significant mortality risk were postoperative rise in creatinine and the Parsonnet score, a risk stratification score previously studied on patients at our institution $[25,26]$. These findings bring clarity to the approach to interpretation of serial lactate measurements in the post-cardiac surgery patient population.

Both cardiogenic and non-cardiogenic causes for hyperlactatemia exist in our population. The multiple logistic regression models performed here for hyperlactatemia suggest that kidney dysfunction and requirement for insertion of a preoperative IABP are associated with increased risk of postoperative hyperlactatemia. The pathophysiology of the hyperlactatemic state is primarily one of hypoperfusion, resulting in anaerobic metabolism and lactic acid production. Meregalli et al. argued that circulatory dysfunction is present even in critically ill surgical patients without evidence of shock. It can be inferred that the presence of hyperlactatemia indicates "occult hypoperfusion" in certain patients, thus explaining their increased mortality [23]. Interestingly, in our study, acute kidney injury in the postoperative period, defined by the 2007 Acute Kidney Injury Network stage 1 criteria, is highly correlated with hyperlactatemia. From this, we learn that hyperlactatemia is not only a 
result of decreased oxygen delivery, but that it is also affected by end organ dysfunction. Interpretation of lactate trends therefore should take into account such non-cardiogenic factors.

In the cardiac surgery population specifically, perfusion deficits are created while on $\mathrm{CPB}$. As core temperature is increased and $\mathrm{CPB}$ is weaned, perfusion of organs becomes inadequate for demand, resulting in lactic acidosis [27]. In a prospective study, length of time on CPB has been previously suggested to increase the likelihood of developing a postoperative lactatemia $\geq 5.0 \mathrm{mmol} / \mathrm{L} \mathrm{[28]}$. While the perfusion deficits developed during $\mathrm{CPB}$ are undoubtedly contributing to the cardiac surgery patient's anaerobic state in the postoperative period, our results show that $\mathrm{CPB}$ time does not have an independent effect of significance on the development of a postoperative hyperlactatemia $\geq 3.0 \mathrm{mmol} / \mathrm{L}$. This lack of detection of a measurable effect of CPB time on lactate elevation may be due to our lower threshold value for hyperlactatemia.

The lactate produced intraoperatively while on $\mathrm{CPB}$ continues to be detected in the serum postoperatively as it is cleared by the kidneys and liver. In addition to this postoperative "washout phenomenon", perfusion deficits may persist into the recovery period, leading to lactate persistence. We do observe that this development of late hyperlactatemia is associated with higher mortality risk. The continued lactate production post-CPB is not sufficiently explained by a post-CPB washout phenomenon. A short duration of lactate accumulation and an early peak in serum lactate-in other words, a washout-likely engender less morbidity and mortality because of the absence of ongoing perfusion deficits. We therefore deduce that a hyperlactatemia of significance is the result of a state of ongoing hypoperfusion, manifesting as a longer duration of lactate accumulation and a greater rise in serum creatinine.

There are limitations to this study. This retrospective review included a heterogeneous study population with different cardiac pathologies and procedures. Data on the use of inotropes, which remain possible confounders in this study, were not collected. Only patients with an ICU stay greater than $24 \mathrm{~h}$ were included with the rationale that the hyperlactatemia in these patients was of clinical significance. A bias in the cohort analysis may have resulted from this selection criteria. Note that in the matched cohort analysis, both the cohort and corresponding controls had an ICU admission $>24 \mathrm{~h}$.

To summarise the findings of this study, we highlight the concept that the duration of hyperlactatemia is a more important risk factor than the lactate concentration itself. We propose that persistent elevations in lactate, for which time to peak lactate is a surrogate measurement, are due to a state of ongoing hypoperfusion, leading to a significant increase in mortality risk. This is in contrast to an early lactate rise which represents a washout phenomenon.

\section{Conclusions}

Cardiac surgery patients presenting with late peaking blood lactate $>30 \mathrm{~h}$ post-operatively are at increased risk for poor ICU outcome and mortality. Lactate persistence is a better measurement of prognosis than peak lactate in post-CPB patients. Patients under a state of persistent hypoperfusion, as opposed to a simple post-CPB lactate washout, are at risk for an increased frequency of major postoperative complications and mortality.

\section{Competing interests}

The authors declare that they have no competing interests.

\section{Authors' contributions}

NM and KK were responsible for study concept and design; data acquisition/ analysis; data interpretation; and drafting and revision of the manuscript. SI contributed substantially to data analysis and interpretation and the writing of this manuscript. BD is responsible for the cardiac database and contributed to data interpretation and manuscript review. All authors revised and approved the manuscript.

\section{Acknowledgments}

We would like to acknowledge Laura Banici for her assistance with the management of ethics approvals and Isabelle Lussier for her assistance with the ICU database queries. NM received research bursaries from the McGill University Faculty of Medicine (Mach-Gaensslen Foundation, Edward Beatty Research Award, Clarke McLeod Scholarship). No external funding bodies were involved in data collection, study design/analysis or in the writing of this manuscript.

\section{Author details}

'Division of General Surgery, Vancouver General Hospital, 950 West 10th Avenue, Vancouver, Canada. ${ }^{2}$ Department of Nephrology, McGill University Health Centre, Montréal, Canada. ${ }^{3}$ Division of Cardiothoracic Surgery, McGill University Health Centre, Montréal, Canada. ${ }^{4}$ Departments of Surgery and Critical Care Medicine, McGill University Health Centre, 1650 Cedar Ave. L9.411, Montréal, QC H3G 1A4, Canada.

Received: 19 October 2015 Accepted: 12 January 2016

Published online: 24 February 2016

\section{References}

1. Boldt J, Piper S, Murray P, Lehmann A. Case 2-1999 severe lactic acidosis after cardiac surgery: Sign of perfusion deficits? J Cardiothorac Vasc Anesth. 1999:13(2):220-4.

2. Okorie $\mathrm{ON}$, Dellinger $\mathrm{P}$. Lactate: biomarker and potential therapeutic target. Crit Care Clin. 2011;27(2):299-326.

3. Mustafa I. Effect of cardiopulmonary bypass on lactate metabolism. Intensive Care Med. 2003:29(8):1279-85.

4. Luft FC. Lactic acidosis update for critical care clinicians. J Am Soc Nephrol. 2001;12 suppl 1:S15-9.

5. McNelis J, Marini CP, Jurkiewicz A, Szomstein S, Simms HH, Ritter G, et al. Prolonged lactate clearance is associated with increased mortality in the surgical intensive care unit. Am J Surg. 2001;182(5):481-5.

6. Attanà $P$, Lazzeri C, Picariello C, Dini CS, Gensini GF, Valente S. Lactate and lactate clearance in acute cardiac care patients. Eur Heart J Acute Cardiovasc Care. 2012;1(2):115-21.

7. Maillet JM. Frequency, risk factors, and outcome of hyperlactatemia after cardiac surgery. Chest. 2003;123(5):1361-6.

8. Kogan A. The impact of hyperlactatemia on postoperative outcome after adult cardiac surgery. J Anesth. 2012;26(2):174-8

9. Zante B, Kubik M, Reichenspurner H. Lactate level as prognostic factor of mortality in patients after cardiac surgery. Thorac Cardiovasc Surg. 2010;58:43.

10. Mirmohammad-sadeghi M. Relationship between serum lactate levels and morbidity outcomes in cardiovascular patients after CABG. J Surg Pak Int. 2008;13:2.

11. Toraman F. Lactic acidosis after cardiac surgery is associated with adverse outcome. Heart Surg Forum. 2004;7(2):155-9. 
12. Yılmaz Ş, Yurtseven N, Tuygun AK, Yavuz Y, Canik S. Hyperlactatemia after coronary artery bypass surgery: risk factors and effect on mortality. Turkish J Thorac Cardiovasc Surg. 2011;19(1):30-5.

13. Hatherill M. Serum lactate as a predictor of mortality after paediatric cardiac surgery. Arch Dis Child. 1997;77(3):235-8.

14. Maarslet $\mathrm{L}$. Lactate levels predict mortality and need for peritoneal dialysis in children undergoing congenital heart surgery. Acta Anaesthesiol Scand. 2012;56(4):459-64.

15. Demers P. Outcome with high blood lactate levels during cardiopulmonary bypass in adult cardiac operation. Ann Thorac Surg. 2000;70(6):2082-6.

16. Ranucci M. Central venous oxygen saturation and blood lactate levels during cardiopulmonary bypass are associated with outcome after pediatric cardiac surgery. Crit Care. 2010;14:4

17. Ranucci M. Anaerobic metabolism during cardiopulmonary bypass: predictive value of carbon dioxide derived parameters. Ann Thorac Surg. 2006;81(6):2189-95.

18. Ranucci M. Hyperlactatemia during cardiopulmonary bypass: determinants and impact on postoperative outcome. Crit Care. 2006;10:6.

19. Marty P. Lactate clearance for death prediction in severe sepsis or septic shock patients during the first 24 hours in Intensive Care Unit: an observational study. Ann Intensive Care. 2013;3:1.

20. Donnino MW. Effective lactate clearance is associated with improved outcome in post-cardiac arrest patients. Resuscitation. 2007;75(2):229-34.

21. Nguyen $\mathrm{H}$, Bryant $\mathrm{HB}$. Early lactate clearance is associated with improved outcome in severe sepsis and septic shock. Crit Care Med. 2004;32(8):1637-42.

22. Bakker J. Serial blood lactate levels can predict the development of multiple organ failure following septic shock. Am J Surg. 1996;171(2):221-6.

23. Meregalli A. Occult hypoperfusion is associated with increased mortality in hemodynamically stable, high-risk, surgical patients. Crit Care. 2004;8(2):60-5.

24. O'connor $\mathrm{E}$, Fraser J. The interpretation of perioperative lactate abnormalities in patients undergoing cardiac surgery. Anaesth Intensive Care. 2012;40(4):598-603.

25. de Varennes B, Lachapelle K, Cecere R, Ergina P, Shum-Tim D, Tchervenkov C, et al. Application of the Parsonnet scoring system for a Canadian cardiac surgery program. Can J Cardiol. 2007;23(13):1061-5.

26. Bernstein $A D$, Parsonnet $V$. Bedside estimation of risk as an aid for decisionmaking in cardiac surgery. Ann Thorac Surg. 2000;69(3):823-8.

27. Landow L. Splanchnic lactate production in cardiac surgery patients. Crit Care Med. 1993;21(2):84-91.

28. Raper RF, Cameron G, Walker D, Bowey CJ. Type B lactic acidosis following cardiopulmonary bypass. Crit Care Med. 1997;25(1):46-51.

\section{Submit your next manuscript to BioMed Central and we will help you at every step:}

- We accept pre-submission inquiries

- Our selector tool helps you to find the most relevant journal

- We provide round the clock customer support

- Convenient online submission

- Thorough peer review

- Inclusion in PubMed and all major indexing services

- Maximum visibility for your research

Submit your manuscript at www.biomedcentral.com/submit

) Biomed Central 